\title{
Effect of Plasma Treatment on Microstructure and Surface of Glass for Plastic-Based Composite
}

\author{
A. Nakahira*, Y. Suzuki**, S. Ueno***, H. Akamizu*, K. Kijima* and S. Nishijima*** \\ *Department of Chem. and Materials Tech., Kyoto Institute of Technology, Gosho Kaido-cho, Matsugasaki, \\ Sakyo-ku, Kyoto 606-8585, Japan; **National Industrial Research Institute of Nagoya, 1-1 Hirate-cho, Kita-ku, \\ Nagoya 462-8510, Japan; ***ISIR, Osaka University, 8-1 Mihogaoka, Ibaraki, Osaka 567, Japan
}

\begin{abstract}
Glass fibers and sheets were treated by the low temperature plasma process working with argon atmosphere in order to develop high performance glass fiber reinforced plastic (GFRP). In particular, surface properties, such as roughness and wetting behavior of glass fiber and sheet, were examined with plasma treatments. The surface structure of plasma-treated glass samples was observed by scanning electron microscopy (SEM) and atomic force microscopy (AFM), and the relationship between the surface structure and the wettability was discussed. Interfacial shear strength between the plasma-treated fiber and epoxy resin was evaluated. The argon plasma treatment process improved the interfacial shear strength up to $160 \%$ of the untreated samples. The nanometer-level surface roughness of glass fiber with plasma treatment played an important role in the increase in interfacial fracture behavior. It was found that the plasma treatment process was effective for fabricating high performance GFRP.
\end{abstract}

\section{INTRODUCTION}

High performance glass and ceramic fibers (for example, Nicalon and Tyranno) are indispensable for developing strong, tough fiber-reinforced ceramic matrix composites (FR-CMC) and fiber-reinforced plastic matrix composites (FR-PMC) /1/. In order to apply FR-CMC and FR-PMC into structural components under severe conditions, however, a further improvement in the mechanical properties, such as interfacial shear strength, is of prime importance $/ 2 /$.
Surface treatments of the fibers are promising methods to improve the interfacial shear strength between fiber and matrix. For PMC, various surface treatment processes by wet chemical or dry physical techniques have been studied to modify the fiber surface so as to control the interface between the fiber (glass or carbon fiber) and the polymer matrix /3/. For example, wet chemical processing such as coupling agent treatment and chemical etching, and dry physical processing such as oxidative treatment and plasma treatment have been widely investigated $/ 4 /$. In particular, the improvement of the interfacial bonding between the fiber and matrix for FR-PMC by plasma treatment is an effective approach, because this dry process has the advantage of less environmental pollution, only near-surface modification, and applicability to any complex shaped sample $/ 5 /$.

Among the several plasma treatments, glow discharge - in other words, cold plasma treatment - has advantages that only the surface layer of the fiber is usually modified without severely affecting the fiber properties $16 \%$. The cold plasma treatment can be conducted under various gas phases; plasma treatments with reactive-gas systems (e.g. nitrogen, oxygen and ammonia gases) sometimes result in severe surface damage to the fiber surface. On the other hand, those with inert gas systems (e.g. helium and argon gases) enable the surface structure and roughness to be modified only near the surface layer of the fiber, resulting in the modification of its surface energy and functionality 171 .

The purpose of this paper is to examine the effect of argon plasma treatment on glass surfaces by microscopic evaluation by SEM and AFM and to evaluate the interfacial shear strength between the glass fiber and 
epoxy with the pull-out test of fiber embedded with epoxy resin. The effects of plasma treatment on the surface structure and mechanical properties of glass fibers and sheet are discussed.

\section{EXPERIMENTAL PROCEDURE}

\subsection{Materials}

E-glass was used as a reinforcement material. E-glass is a general name of glasses containing less than $0.8 \mathrm{wt} \%$ of alkali oxides. Thus, it is sometimes called "no-alkali glass". Table 1 shows the composition of Eglass used. In the present study, sheet and fiber forms of E-glass were used. E-glass sheets were cut with a diamond blade into of $10 \times 10 \times 5 \mathrm{~mm}$ dimensions and polished mirror-like with diamond paste below $0.1 \mu \mathrm{m}$. A strand of E-glass consisted of 200 fibers with a diameter of $9 \mu \mathrm{m}$ each. The sizing materials on the surface of the glass fiber was removed by thermal treatment, heat-treated at $300^{\circ} \mathrm{C}$ for $3 \mathrm{~h}$ in air.

Table 1

Composition of E-glass

\begin{tabular}{lc}
\hline composition & wt\% \\
\hline $\mathrm{SiO}_{2}$ & 53.5 \\
$\mathrm{Al}_{2} \mathrm{O}_{3}$ & 15.0 \\
$\mathrm{CaO}$ & 17.5 \\
$\mathrm{MgO}$ & 4.5 \\
$\mathrm{~B}_{2} \mathrm{O}_{3}$ & 8.5 \\
$\mathrm{Alkali} \mathrm{oxide}$ & 0.4 \\
$\mathrm{Fe}_{2} \mathrm{O}_{3}$ & 0.2 \\
\hline
\end{tabular}

\subsection{Plasma treatment}

The plasma equipment used in the present work is illustrated in Fig. 1. The equipment consisted of a Pyrex reaction chamber, a gas inlet and a vacuum chamber. The E-glass fiber and sheet samples were supported on a jig made of boron nitride, mounted in the center of the chamber, and plasma-treated. The reaction chamber was inductively coupled to the radio-frequency (R.F.) power supply operated at $4 \mathrm{MHz}$. The chamber was evacuated

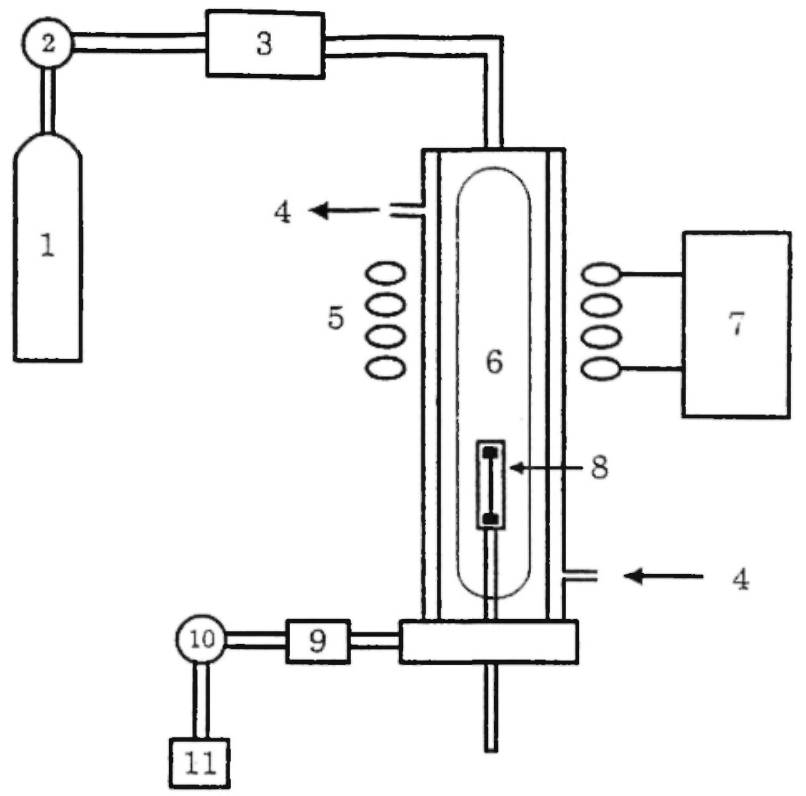

1. gas tank

2. pressure regulator

3. mass flow controller

4. cooling water

5. work coil

6. glow discharge

7. R.F. generator

8. specimen

9. pressure gauge

10. needle valve

11. vacuum pump

Fig. 1: Illustration of plasma equipment used in the present work.

to $2 \mathrm{~Pa}$ with a mechanical pump and then purged well with argon before plasma initiation.

The argon plasma was initiated under a pressure of $60 \mathrm{~Pa}, 90 \mathrm{~Pa}$, and $120 \mathrm{~Pa}$ respectively at the required power level. During plasma treatment, the pressure in the chamber was measured using a capacitance manometer. In all treatments, plasma treatment time was 120s. E-glass fiber and sheet samples were supported on a boron nitride jig, mounted in the center of the chamber and plasma-treated at $100 \mathrm{~W}, 200 \mathrm{~W}$, and $300 \mathrm{~W}$.

\subsection{Evaluation}

SEM observations of glass sheets and fibers were done with plasma treatments. The surfaces of glass sheets were also observed by AFM (Nanoscope III, Digital Instruments) for more detailed observation. At the same time, the roughness of glass sheets with plasma treatments was measured by using AFM. The 
surface wettability of E-glass sheet with plasma treatments was evaluated with the contact angle. The contact angle of E-glass sheet samples with the various plasma treatments was measured with distilled water at ambient temperature using a face-contact-angle meter (Kyowa-Kagaku Co.).

To evaluate the effects of plasma treatment on mechanical properties, a tensile test was performed. Eglass fiber was mounted on aluminum-plate $(10 \times 10 \times 1$ $\mathrm{mm}$ ), using epoxy resin (Araldite, Ciba-Geigy). A tensile test (i.e., pull-out test), which is shown in Fig. 2, was performed for measuring the interfacial shear strength between the E-glass fiber and the epoxy resin using an Instron machine at a constant cross-head speed of $1 \mathrm{~mm} / \mathrm{min}$. Interfacial shear strength, $\tau$, was

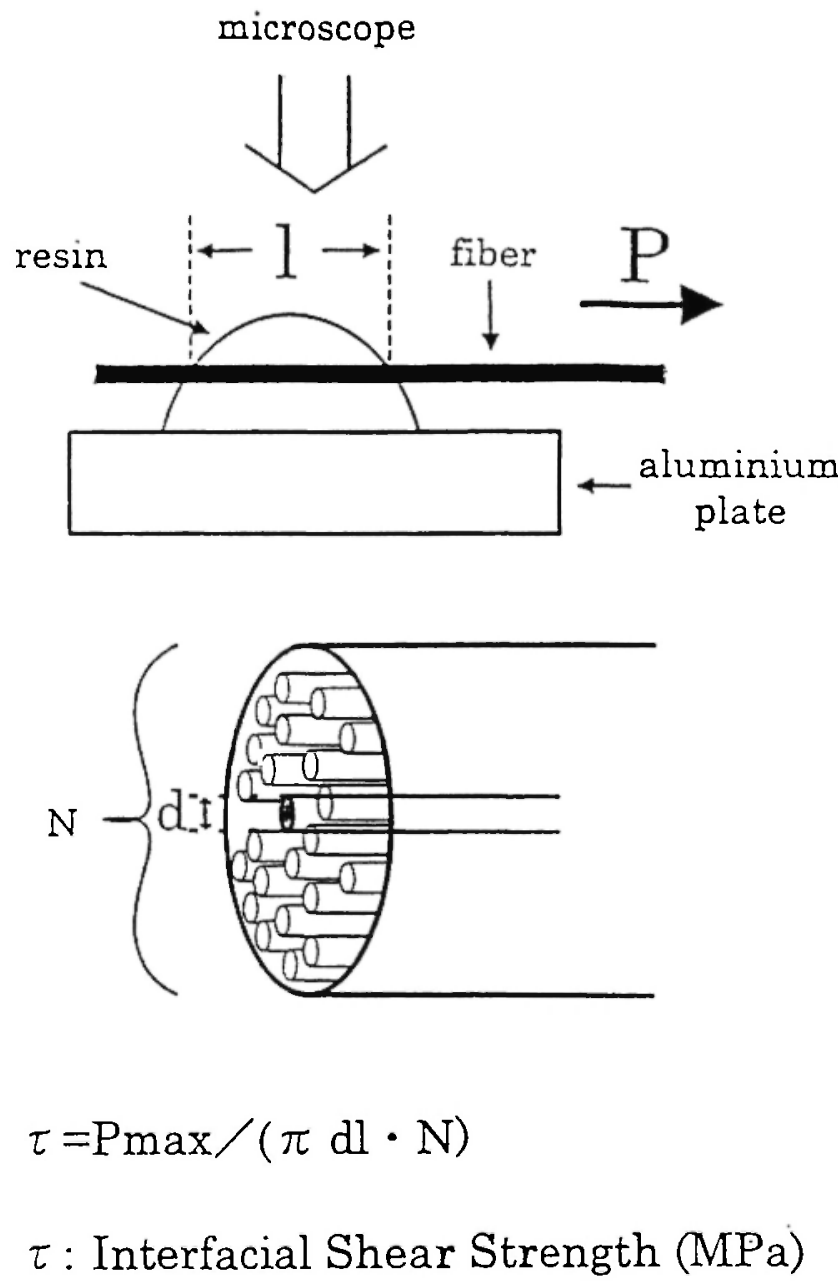

Fig. 2: Schematic drawing of the pull-out test. calculated by the following equation:

$$
\tau=P /(\pi d l N)
$$

where $P$ : load, $d$ : fiber diameter, $l:$ fiber length embedded within epoxy resin, and $N$ : number of fibers of a strand, $N=200$, in this work. The embedded fiber length, $l$, was measured by the micrometer of optical scope. The interfacial shear strengths of 5 specimens were averaged. Fiber surfaces pull-out from the epoxy/ E-glass fiber specimens after the tensile test were observed by SEM.

\section{RESULTS AND DISCUSSION}

Figure 3 shows the relationship between the contact angle and gas pressure with argon plasma treatment. As is well-known, the performance of plasma treatment is dependent on the power and the gas pressure $/ 8 /$. In this experiment, the contact angle values were dependent on power and gas pressure of plasma treatment. The aspolished mirror-like E-glass sheet had the contact angle of approximately $66.2^{\circ}$. In addition, the surface of Eglass mechanically ground by the grinding with $\# 400$ diamond wheel (approximately $30 \mu \mathrm{m}$ in roughness)

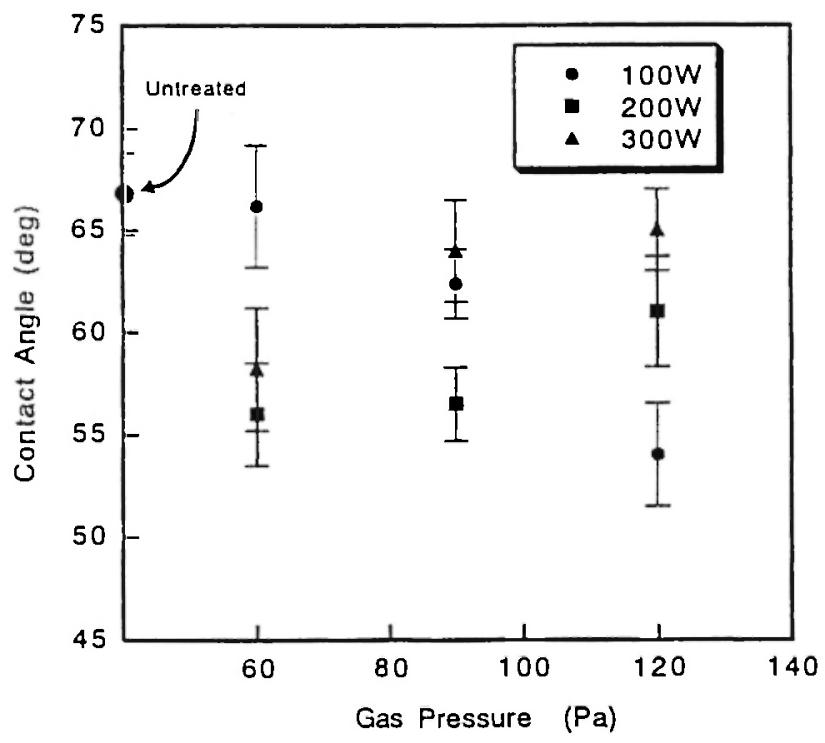

Fig. 3: The relationship between the contact angle and gas pressure with argon plasma treatments. 
indicated a rather high contact angle of approximately $80^{\circ}$. Such an increase in the contact angle (i.e., decrease in the wettability) by the increase in roughness (here, several tens to hundreds micrometer level) can be satisfactorily explained by proposed models in the literature, such as the metastable equilibrium configuration model $/ 9 /$ and the hemispherical closed-packed model $/ 10 /$. On the other hand, the contact angle of Eglass sheet after argon plasma treatment decreased with the gas pressure during plasma treatment of $100 \mathrm{~W}$, although the surface roughness was slightly increased as shown later. The higher power plasma treatment of $200 \mathrm{~W}$ and $300 \mathrm{~W}$ also lowered the contact angle compared to the untreated sample, though the contact angle increased with increasing gas pressure. These results showed that the contact angle between E-glass and water was dependent on the roughness after the plasma treatment. So the wettability of E-glass was found to be varied by the plasma conditions, such as power level and gas pressure on the plasma treatment. Therefore it can be stated that the plasma treatment makes the surface of E-glass more hydrophilic, as pointed out by Krishnamurthy et al. $/ 1 \mathrm{l} /$. The decrease in contact angle was achieved not only by the removal of surface contamination, but also the modification of the surface chemistry of E-glass by plasma treatment.

The surfaces of E-glass sheets with plasma treatments were observed by AFM to quantitatively evaluate the surface morphology. Fig. 4 shows the typical AFM images of the surfaces of E-glass sheets with plasma treatment $(100 \mathrm{~W}, 200 \mathrm{~W}$ and $300 \mathrm{~W})$ with the gas pressure of $60 \mathrm{~Pa}$ and $120 \mathrm{~Pa}$. The as-polished surface of E-glass sheets was completely flat. In the case of the roughness data for $300 \mathrm{~W}$ plasma, the E-glass sheet plasma treated with the gas pressure of $120 \mathrm{~Pa}$ exhibited a rougher surface than that with the gas pressure of $60 \mathrm{~Pa}$, as is obvious in Fig. 4. The lower plasma powers, $100 \mathrm{~W}$ and $200 \mathrm{~W}$, induced less damage on the surface of E-glass sheet, compared to $300 \mathrm{~W}$ plasma.

The results of roughness measurements of E-glass sheet surface by AFM are summarized in Fig. 5 . The aspolished E-glass sheet showed a roughness of only $0.004 \mu \mathrm{m}$. E-glass surface roughness slightly increased linearly with gas pressure on plasma treatment, but the roughness was still at nanometer (or submicron) level.
As previously shown, the rough surface of E-glass mechanically ground with a diamond wheel indicated a much higher contact angle of about $80^{\circ}$, compared with the as-polished sheet. As a result, the E-glass sheet modified by plasma treatments showed lower contact angles than the as-polished specimen, whereas the Eglass sheet ground by grinding mechanically showed a higher contact angle than the as-polished specimen. It therefore became evident that the increase in surface roughness of E-glass at nanometer level did not significantly affect the contact angle and the roughness increase at the micrometer scale due to mechanical grinding with a $\# 400$ diamond wheel (approximately 30 $\mu \mathrm{m}$ in roughness) increased the contact angle. The difference between the plasma treated and as-polished E-glass sheet may be associated with the modification of the surface chemistry and functionality of the E-glass sheet by the plasma treatment. Yasuda et al. /12/ reported that argon plasma treatment on polymer increased its hydrophilicity, and they explained that highly reactive radicals produced by the argon plasma reacted with the external oxygen after the plasma treatment, and they formed polar functional groups on the surface. In the glass system, it can be thought that dangling bonds produced by the plasma treatment may form more silanol groups with the water vapor after the plasma treatment, and they improve the hydrophilicity.

Figure 6 shows SEM images of E-glass fiber after plasma treatment. The effect of power levels and gas pressures on the plasma conditions in the fiber roughness change was examined after the plasma treatments. From the results of SEM observation for Eglass fiber, the plasma treatment induced a certain damage on the surface of E-glass fiber, though the surfaces of the fibers treated at $90 \mathrm{~Pa}$ were not shown here. The surface of E-glass fiber was a little damaged by the plasma treatment of $100 \mathrm{~W}$ and $200 \mathrm{~W}$ power with high gas pressure, although there was not a large difference between fiber surfaces treated at $90 \mathrm{~Pa}$ and $60 \mathrm{~Pa}$ on both $100 \mathrm{~W}$ and $200 \mathrm{~W}$ in plasma treatment. In the $300 \mathrm{~W}$ plasma treatment, samples treated with gas pressure of $60 \mathrm{~Pa}$ showed rougher surface and sometimes surface striations were observed. The dependence of pressures in the plasma on the morphology of fiber surface was varied with the plasma power levels. Plasma treatments with higher power levels were found 


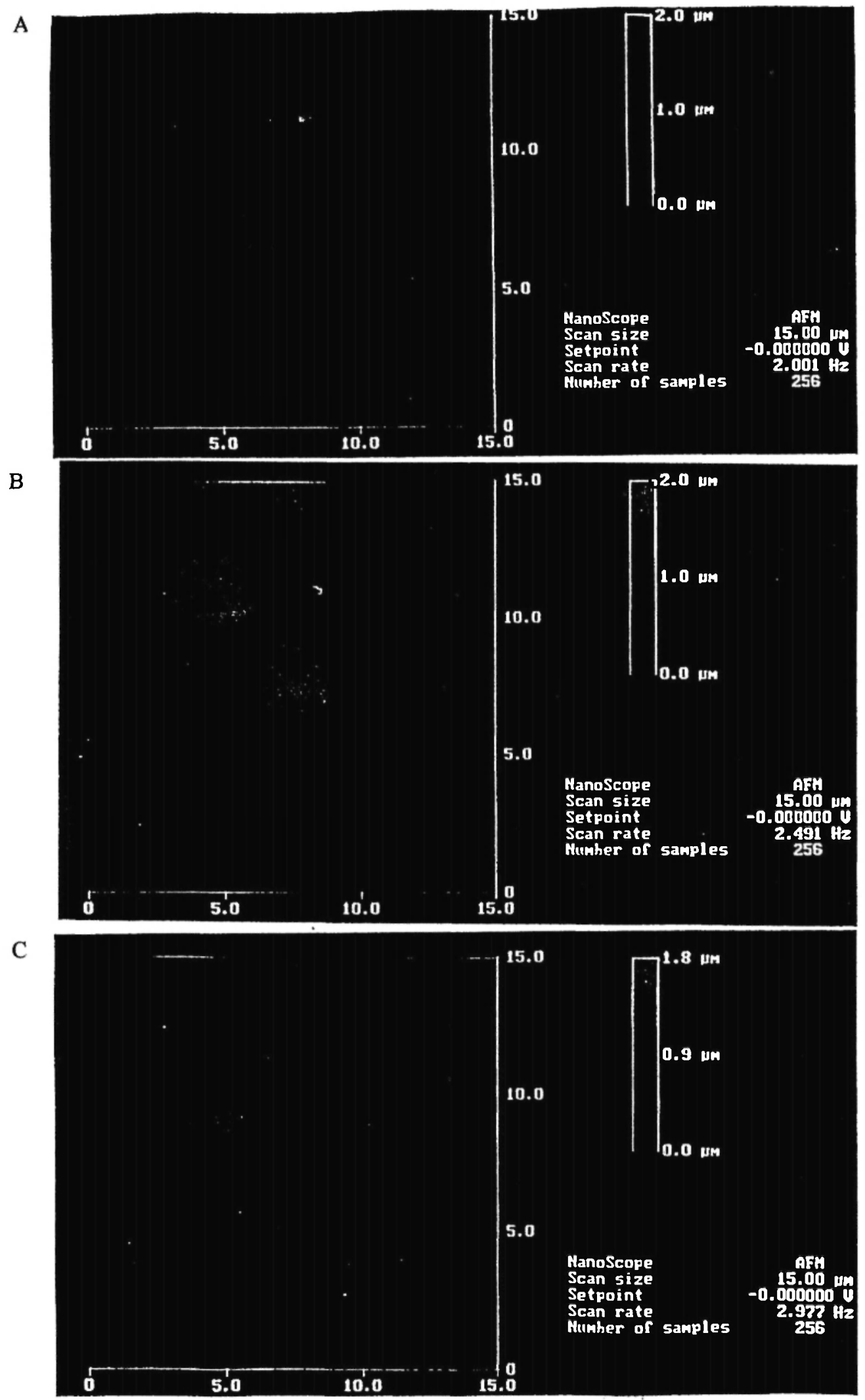

Fig. 4: Typical AFM images of surface of E-glass sheet with plasma treatment with $300 \mathrm{~W}$ under gas pressures of 60 to $120 \mathrm{~Pa}$ : (A) as-polished, (B) $60 \mathrm{~Pa}$, and (C) $120 \mathrm{~Pa}$. 


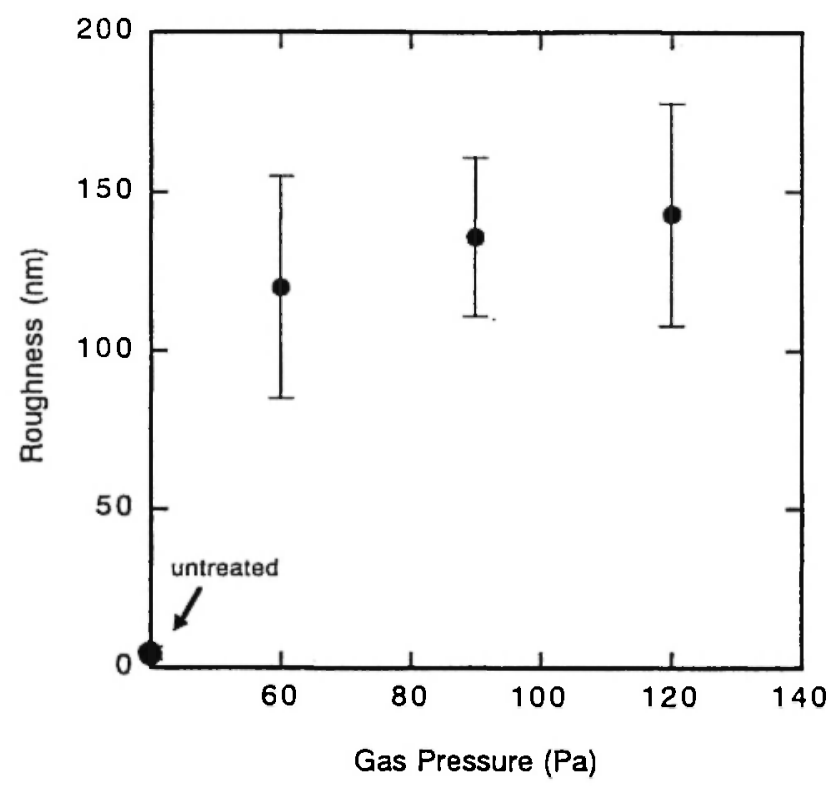

(A)

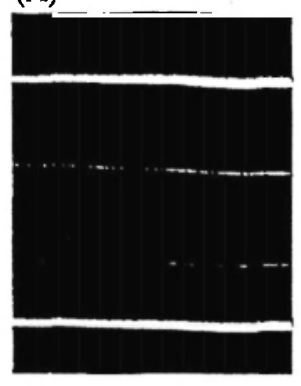

(D)

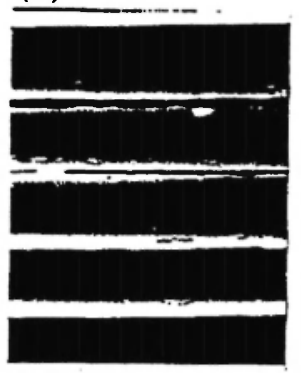

(G)

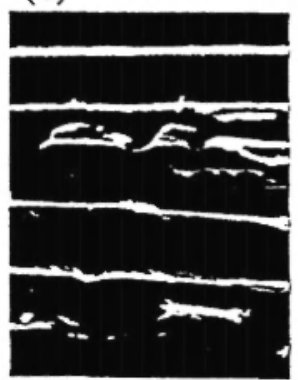

(B)

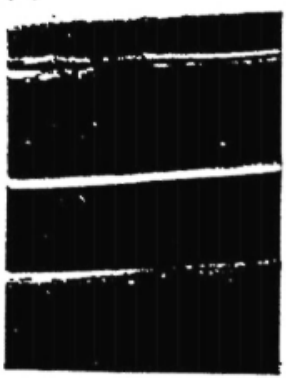

(E)

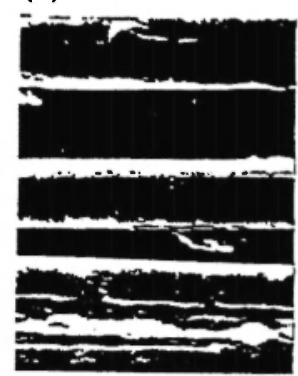

(F)

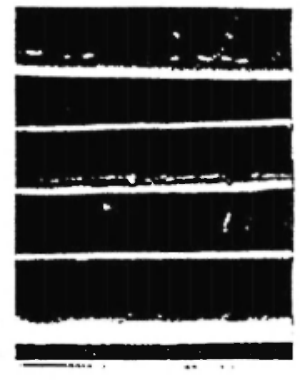

(F)

)

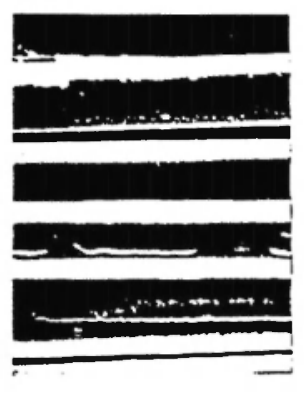

(C) surface of E-glass sheet with plasma treatments with the plasma power.

to lead to more severe damage of the fiber. The SEM observation implies that plasma treatments under too severe conditions may decrease the intrinsic fiber strength, even for mild inert-gas systems.

The effect of gas pressure on the interfacial shear strength with plasma treatment of 100,200 and $300 \mathrm{~W}$ power is shown in Fig. 7. The E-glass fiber/epoxy samples plasma-treated with the power of $100 \mathrm{~W}$ and $200 \mathrm{~W}$ tended to show an increase in interfacial shear strength with gas pressure up to $90 \mathrm{~Pa}$. The sample with $300 \mathrm{~W}$ plasma treatment showed the maximum inter-

Fig. 5: The effect of gas pressure on the roughness of

$15 \mu \mathrm{m}$

Fig. 6: SEM images of the E-glass fiber after plasma treatments: (A) untreated, (B) 100W, $60 \mathrm{~Pa},(\mathrm{C}) 100 \mathrm{~W}, 120 \mathrm{~Pa}$, (D) $200 \mathrm{~W}, 60 \mathrm{~Pa}$, (E) 200W, $120 \mathrm{~Pa}$, (F) 300W, $60 \mathrm{~Pa}$, and (G) $300 \mathrm{~W}, 120 \mathrm{~Pa}$. 


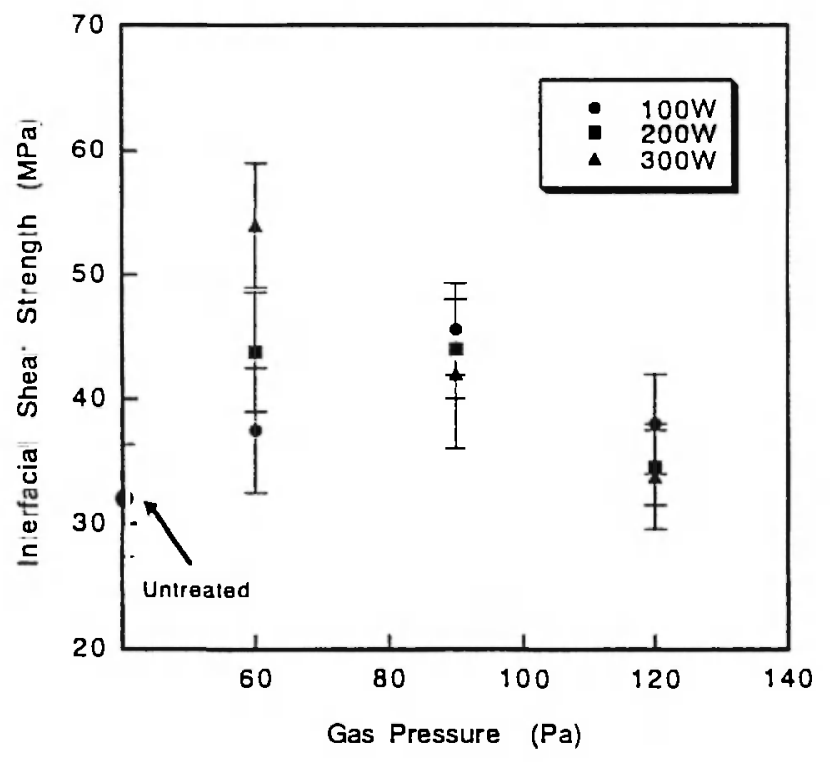

facial shear strength at gas pressure of $60 \mathrm{~Pa}$ and decreased with gas pressure over $90 \mathrm{~Pa}$. An increase of approximately $60 \%$ in the interfacial shear strength for epoxy/E-glass fiber was achieved by argon plasma treatment. However, a significant increase in roughness from severe damage resulted in a decrease in interfacial shear strength.

Figure 8 shows the fiber surfaces pulled out from the epoxy/E-glass fiber specimens after the tensile test. For plasma-treated specimens, the matrix resin was adhered to the fibers (Fig. 8(B) and (C)). The achievement of

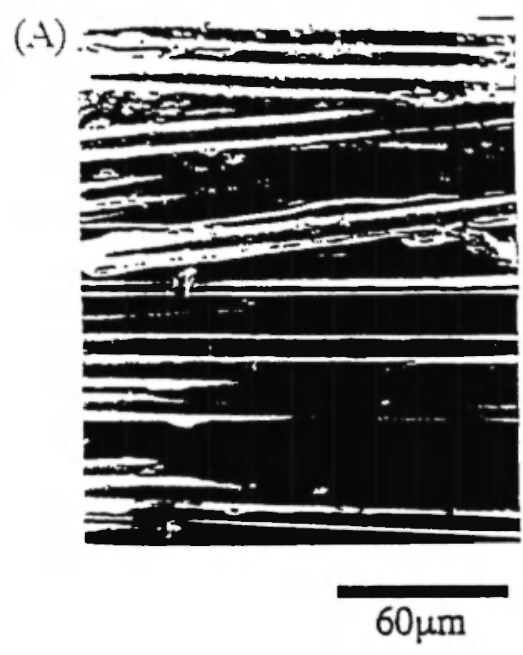

(B)

Fig. 7: The effect of gas pressure on the interfacial shear strength.
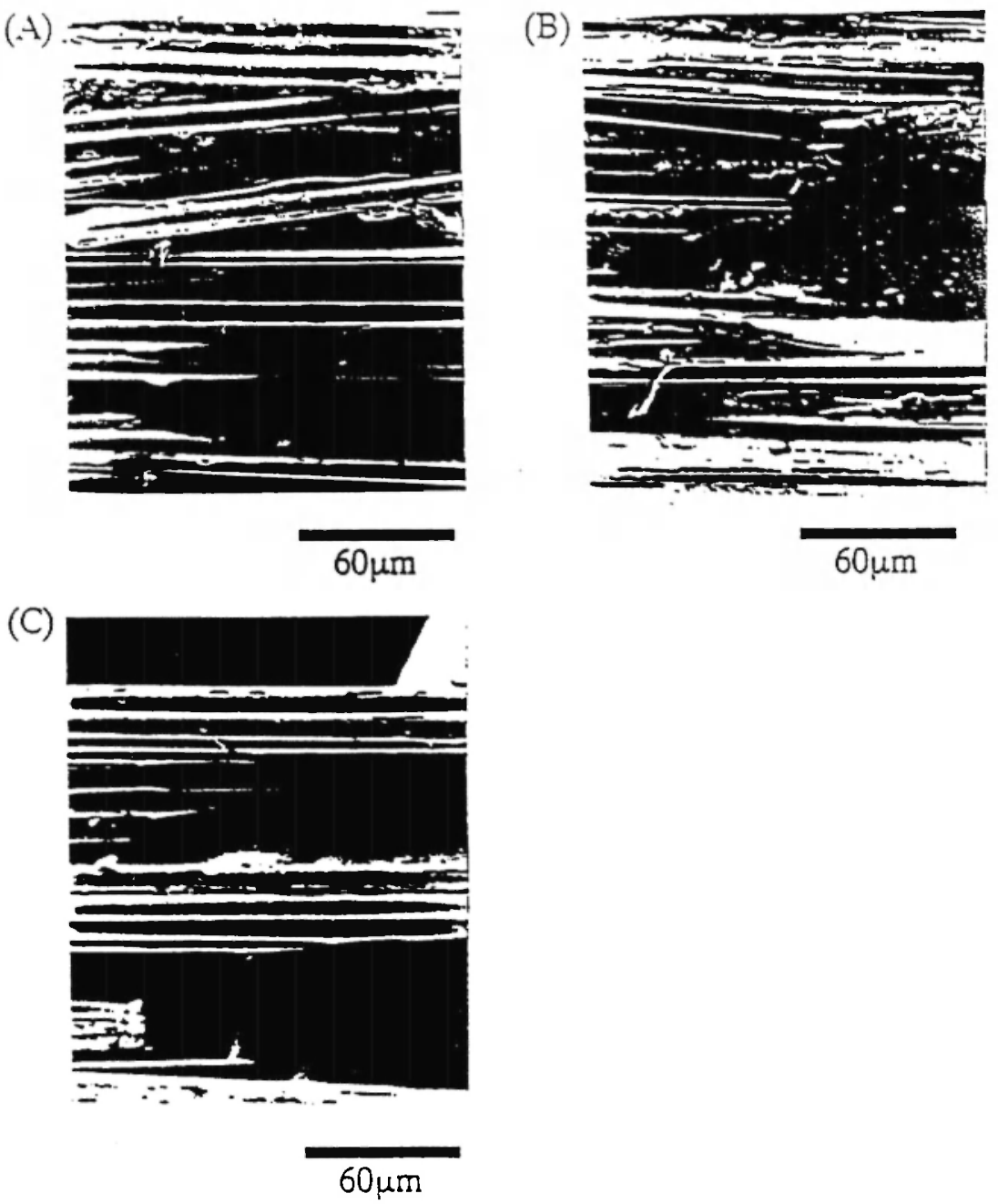

Fig. 8: SEM images of E-glass/epoxy samples after the pull-out test: (A) untreated, (B) $300 \mathrm{~W}, 60 \mathrm{~Pa}$, and (C) $300 \mathrm{~W}$, $120 \mathrm{~Pa}$. 
optimum roughness on glass fiber surfaces resulted in an increase in the adhesive properties, which would lead to an increase in the interfacial shear strength, as shown in Fig. 7.

As is clearly shown from the results of surface observation by AFM and SEM and interfacial shear strength, an increase in roughness on a nanometer scale, for example $0.1-0.2 \mu \mathrm{m}$, leads to an increase in contact surface area between polymer and E-glass fiber and results in high interfacial bonding. As a result of an increase in interfacial bonding, the increase in adhesive strength and interlocking effect was presumably achieved $/ 13 /$. Therefore the changes in interfacial shear strength were probably attributable to improvement in wettability between fiber and matrix, and optimum increase in roughness on the surface of E-glass fibers by argon plasma treatment.

\section{CONCLUSIONS}

The effects of argon plasma treatment on glass surfaces were examined by microscopic observations using SEM and AFM. The roughness and damage of the E-glass sheet and fiber surfaces were dependent on the plasma power and gas pressure. Wettability of surface of the E-glass sheet was enhanced by argon plasma treatments. Although the rough surface on a micrometer scale tends to have higher contact angle, the increase in surface roughness of E-glass at nanometer level was found not to be reflected in the contact angle, but to be associated with the modification of surface chemistry of the E-glass sheet on the control of contact angle by plasma treatments.

The plasma treatment increased the interfacial shear strength between glass fiber and epoxy resin. From these results, it was found that the argon plasma treat- ment of glass fiber produced an improvement in wettability and an optimum increase in roughness on the surface of E-glass fiber, and resulted in the improvement of the interfacial shear strength between E-glass fiber and epoxy.

\section{REFERENCES}

1. P.G. Karandikar, T.W. Chou and A. ParviziMajidi, J. Mater. Sci., 32, 6459 (1997).

2. C.Y. Kim, G. Suryani and D.A.I. Goring, J. Polym. Sci., Part C, 30, 533 (1970).

3. A. Rose and J.T.A. Poolock, J. Mater. Sci., 23, 1752 (1988).

4. M. Breznick, J. Banbaji, H. Guttmann and G. Marom, Polym. Commun, 28, 55 (1987).

5. R. Foerch, N.S. Mcintyre and R.N.S. Sodhi, J. Appl. Polym. Sci., 40, 1903 (1990).

6. Y. Iriyama and H. Yasuda, J. Appl. Polym. Sci., Appl. Polymer Symp., 42, 97 (1988).

7. J.R. Hall, C.A.L. Westerdahl, A.T. Devine and M.J. Bodnar, J. Appl. Polym. Sci., 13, 2085 (1969).

8. H. Yasuda, in: Thin Film Processes, J.L. Vossen and W. Kern (Eds.), Academic Press, New York, 1978; p. 361.

9. S.J. Hitchcock, N.T. Carroll and M.G. Nicholas, J. Mater. Sci., 16, 714 (1981).

10. H. Nakae, R. Inui, Y. Hirata and H. Saito, Acta Mater., 46, 2313 (1998).

11. V. Krishnamurthy and I.L. Kamel, J. Mater. Sci., 24, 3345 (1989).

12. H. Yasuda, H.C. Marsh, S. Brandt and C.N. Reilley, J. Polym. Sci., Polym. Chem. Ed., 15, 991 (1977).

13. M. Sun, B. Hu, Y. Wu, Y. Tang, W. Huang and Y. Da, Composites Sci. and Technol., 34, 353 (1989). 